\title{
Making Contact in an exhibition zone: Displaying contemporary cultural diversity in Donegal, Ireland, through an installation of visual and material portraits
}

\author{
Harriet Purkis*
}

\begin{abstract}
The 'museum as contact zone' (Clifford 1997: 192) has been a concept that has theoretically framed the inclusion of different cultures in museums. The contact zone concept has been revisited, for example by Boast 2011. Further, the idea of the 'dialogic contact zone' (Witcomb 2003; Bennett 2006) is used in relation to exhibition communication techniques that aim to establish a dialogue on cultural diversity between visitors, exhibitions and curators. This paper sets out to reframe the contact zone concept, by considering both the nature and form of contact in an exhibition. The method used is the practical curation of one exhibition by the author in Ireland called Destination Donegal. The main argument is that a curatorial production focused on individual people can create an empathetic contact zone between individual subjects and visitors, achieved through the non-verbal display language of art installation using multimedia portraits.
\end{abstract}

Key words: cultural diversity, exhibition, contact zone, material culture, art installation

Introduction

The meeting of different cultures in museums has been conceptualized as a 'contact zone' (Clifford 1997: 192), that is, museums are seen as places of encounter, exchange and connection between people in a globalized world. For Andrea Witcomb (2003: 128-64), the exhibition itself can become a 'contact zone' through the use of interactive media and communication strategies. It is within this theoretical framework that I present the example of an exhibition of multimedia personal portraits of people from different cultural backgrounds living in a rural county in Ireland.

The paper begins with a short description of the exhibition called Destination Donegal, ${ }^{1}$ curated by the author. The exhibition is used as an example in making a physical exhibition as a contact zone. I aim to explore how emotional and personal contact at a person-to-person level can be created, by discussing both the process of participant involvement that created the content of the exhibition and the process of production that created the physical form used to convey this content. The latter is explored through the design strategy based on the language of art installation using visual and material sources including life-sized photographic portraits of people, video close-ups of people's faces and their clothes. ${ }^{2}$ The paper then discusses the theoretical concept of the contact zone, and goes on to critique a selection of previous migration and cultural diversity exhibitions in order to contextualize Destination Donegal within an international setting. Following this, the Irish economic and social context is discussed, with some Irish examples of exhibitions on migration and cultural diversity. The curatorial process of Destination Donegal is then discussed in terms of the curatorial approaches, the involvement of participants, and the design and communication strategies at work in the final installation. Evidence is included in the form of photographs of the exhibition, extracts from participant interviews, and visitor comments.

The Destination Donegal Exhibition - A Description

This description of the Destination Donegal exhibition introduces the key example used in the 
argument that curatorial production focused on people can achieve an exhibition as contact zone. This description provides a context within which to understand the theoretical discussion and its application to the exhibition's curatorial and production processes.

The purpose of Destination Donegalwas to create an exhibition and art installation about present day cultural diversity. It was curated by the author in 2011 with a small team consisting of a filmmaker, a photographer and a graphic designer, with a budget of $€ 14,000$. The approach of Destination Donegal was to make visible the personal and cultural identities of 12 individuals. The exhibition aimed to focus on these 12 as the subject of the show, rather than on the political and social issues that arise from a culturally diverse society. The exhibition was designed by the curator to allow visitors to get a sense of meeting the individuals in the exhibition space, with the aim of affecting an emotional response. This, it was posited, might lead to understanding and empathy towards different people's lives and experiences. This was achieved by blending approaches and methods from social history curatorship, contemporary collecting, contemporary art practice and material culture studies. Individual personal stories were gathered through a combination of filmed interviews, new portrait photography and the borrowing of personal belongings including clothing and personal effects. The final exhibition featured large-scale visual and material representations of individuals through the display of a set of everyday clothes, life-sized head-to-toe portrait photographs, filmed interview clips, and text panels entirely of the participants' own words with family photos. The exhibition included a hands-on area for visitor interactivity. This included making national flags from Lego; talking to camera in a video booth about migration; and an opportunity for visitors to give feedback and choose an object to take with them if they emigrated, by writing on yellow post-it notes and sticking them to a wall. The exhibition took place in a modern art gallery, not a museum with historic collections. It was conceived as part of a social inclusion initiative of Donegal County Council. By exploring the theoretical concept of the contact zone through exhibition practice in the particular context of an art and social history exhibition in Ireland, I hope to generate new perspectives about the form and nature of presenting cultural diversity in exhibitions.

\section{The contact zone concept in museums}

The contact zone concept, though dated, is currently being revisited in relation to museums and exhibitions. For example, a conference, Re-Visiting the Contact Zone: Museums, Theory, Practice took place in Sweden in $2011 .^{3}$ Exploring the concept in theory and practice adds to this contemporary discussion.

The coining of the term 'contact zone' was by Mary Louise Pratt, in the context of writing and literacy, drawing on the example of children speaking different languages coming together in a classroom space. She extended this 'to refer to social spaces where cultures meet, clash, and grapple with each other, often in contexts of highly asymmetrical relations of power' (Pratt 1991: 34).

By using the concept to discuss cultural mediation in community settings, and to explore unequal power relations based on past colonial relationships, she drew attention to strategies which seek to include and collaborate with people previously considered as 'Other'. Applied in the 1990s in anthropology, the term refers to cross-cultural encounter and is centrally concerned with colonialism (Long 2011: 420). From these roots, it was James Clifford who brought the concept to museums - 'Museums as Contact Zones' (1997: 188-219) - when he argued that colonial power relations are embedded in the way museum collections from around the world in Western museums are interpreted. He advocated 'collaboration and a sharing of authority' in contemporary museums (Clifford 1997: 210), which Rhiannon Mason (2010: 25) has interpreted as enabling a more interactive role for museums, making them more 'a permeable space of transcultural encounter than as a tightly bounded institution disseminating knowledge to its visitors'.

The contact zone concept has generally provided a means to critique projects that involve the participation of people outside the museums from distinct community or ethnic groups. For some the concept is overused, with Kylie Message's view that academics have fetishized the contact zone concept (2009: 128). For others, the unquestioned positive use of the 'contact zone' term has recently been criticized, with Robin Boast (2011: 57) emphasizing 
the continuance of neo-colonialism in the assumptions and practices of museums today, described as, 'the dark underbelly of the contact zone'. He is referring to the way museums still hold onto power in terms of what to collect, whose expertise is provided, and in the way particular meanings of objects are sanctioned. Boast (2011:63) also argues that participants are included on the museum's terms, and museums 'remain sites where the Others come to perform for us, not with us'. This challenge to viewing the contact zone concept as meaning successfully sharing and involving people is supported by others who see the contact zone as a place for contesting rather than collaborating (Alberti and Lynch 2010: 16). A different strand of literature in environment and planning sees the contact zone concept as essentially spatial. One example shows a renewed engagement with a contact zone as a physical space of interaction, enabling 'meaningful contact between different social groups', materials and space, in relation to a community art project (Askins and Pain 2011: 803). It is this 'contact zone as space' that I am interested in considering in relation to an exhibition space.

Curators have made practical use of the term 'contact zone' in different ways. As a fluid concept, able to be reinterpreted and defined through practice, it appears a viable concept to be redefined or reframed. The concept has been used to describe the process of the reinterpretation of historic, non-European museum collections, sometimes by the living descendants of people from the object's country of origin. The contact zone concept has also been used to describe community museums (Crooke 2007: 134) and community projects for socially excluded groups. For example, Glasgow Museums facilitated the setting up of a new local museum in a deprived area called Pollock, described as a 'contact zone' (McLean 2008: 289). These examples validate my approach of making a contact zone as a real space in an exhibition.

The concept has been added to in both theory and practice. It was Andrea Witcomb who first introduced the term 'dialogic' as an extension of the contact zone in 2003, exploring the use of interactivity and media in exhibitions to create a structure for dialogue. The dialogic contact zone in exhibitions about cultural diversity (Hutchinson and Collins 2009: 92-93) has often highlighted an exchange of words (though by no means exclusively) as the main connector in creating a relationship between visitors, participants and curator, by highlighting dialogue and conversations 'across difference' (Witcomb 2009). While some exhibitions communicate the experience of migration, elsewhere the dialogic concept has been considered specifically in relation to democratic discussion about cultural diversity in museums, where dialogue can happen in a respectful and understanding way (Golding 2009: 4). I aim to add to the discussion about contact zones, by concentrating on the term communication rather than dialogue with its foregrounding of words and text. I argue that non-verbal forms of communication - through the example of an installation of visual and material sources in the Destination Donegal exhibition - can enhance the conveyance of individual personal experiences of migration and cultural difference to visitors, going beyond 'objects and text' (Bennett 2006: 63).

Cultural Diversity and Migration in Exhibitions - contexts, approaches and methods

While many reports and studies over the last 20 years in the UK on the theme of cultural diversity concentrate on how and why museums encourage participation and access by culturally diverse groups, in pursuance of a cultural policy determined by the politics of social inclusion, discussion about cultural diversity has not been extensively explored in relation to its physical manifestation in exhibitions. ${ }^{4}$ This paper discusses the physical representation of cultural diversity, as well as the impact of the process of participant involvement on the final exhibition's form and content.

The Destination Donegal exhibition can be seen as one of many addressing the subject, in the context of a 30-year history of museums engaging with the issue. The exhibitions examined in this section were created within key political moments in certain countries, at particular times in history, under the prevailing cultural policy. For example, the Australian museum focus in the 1990s on migration exhibitions is linked to politics promoting multiculturalism (Bennett 2006: 59). While in the UK, the social inclusion agenda in the noughties has promoted a cultural policy presenting museums as agents of social change with the potential to 'promote tolerance, inter-community respect and to challenge stereotypes' (Sandell 2003: 46). However, a broad sweep offers up a continuum between earlier engagements with 'multiculturalism' in Australia, Canada and the USA in the 1990s, to 'social inclusion' and 'cultural diversity' agendas 
from the noughties in the UK and Ireland. There are political reasons, then, for the positive and celebratory (Isar and Anheier 2011) perspective of many exhibitions, as the promotion of multiculturalism, cultural diversity and social inclusion can be seen as incorporated into the aims of the exhibitions. My approach is to offer a critique of cultural diversity and migration exhibitions through the concept of the contact zone, revealing the uses and meanings of the concept in practice.

It is certainly the case that, in many exhibitions, a culturally diverse population is segmented into groups or communities within the 'social inclusion' political agenda. The reason that many exhibitions happen is because they are funded as a result of wider political objectives for an inclusive, multicultural society. Within these projects, final exhibitions are sometimes considered an end point to participatory and access work involving refugees, asylum seekers (Skartveit and Goodnow 2010) or particular ethnic groups (Pahl and Pollard 2010; Shatanawi 2012). The resulting exhibitions are framed by a curatorial process where, for example, visitors may be presented with a history of diverse cultures, or a dialogue, where visitors hear points of view from ethnic communities or groups of asylum seekers about controversial issues. For example, Pahl and Pollard involved Pakistani families in South Yorkshire in an innovative research process, which culminated in a traditional exhibition centred on glass cases containing objects arranged by themes such as gold, textiles and toys. They described this exhibition in Rotherham in March 2007 as a 'contact zone' (Pahl and Pollard 2010:7).

Nevertheless, it is not just government agendas that influence exhibitions; curators, participants and visitors are important. Exhibitions have been seen as becoming 'laboratories of reflexivity and transformation' (Nederveen Pieterse 1997: 124-5), indicating the potential of experimental curatorial practice to contribute within these political agendas. In addition, Rhiannon Mason (2010: 25) argues that communities and visitors exert their 'own forces upon the museum'. This produces a variety of cultural diversity exhibitions, with different aims, curatorial methods and final products. Some see the subject of cultural diversity as a contemporary issue to be discussed, debated and explored in exhibitions (Bonnell and Simon 2007; Cameron and Kelly 2010). Others make exhibitions that are conceived within a community-based approach to museum work (Shatanawi2012). Further, as Sharon Macdonald advocates, an engagement with the complex nature of cultural identities in museums gives them huge potential as sites in which 'post national and transcultural identities' can be expressed (Macdonald 2003: 1). Furthermore, in terms of the actual practice by which curators develop exhibitions, the methods they use to engage with communities, and how these may challenge museum traditions and conventions, it has been suggested that exhibitions about cultural diversity are in the forefront of leading change in established museum exhibition practice (Doering and Lakshmi 2012). Destination Donegalcontributes to changing established exhibition practice.

In terms of curatorial approaches, migration exhibitions have often used 'the suitcase narrative' in the past. This reflects oral history research asking what people brought with them in their suitcase when they came to the country (Witcomb 2009: 53). Other exhibitions located in maritime museums or ports of entry, such as Ellis Island Immigration Museum, focus on the process of arrival. These museums locate people as perpetual immigrants, frozen in time, their identities defined as connected to that past moment in time when they arrived from their home country. A structure is used which allows visitors to read and hear and see the journeys people made through oral history. Individual testimony is part of the communication; it is emotional and personal, yet it is set in the past, and considered as a typical example within the wider narrative of the exhibition that concerns arrival and setting up home.

However, recent practice challenges established ways of considering migration history. The making of a dialogic exhibition form through text and words has been used by Hutchinson who has explored migration in Australia through exhibitions which are, 'embodying and grounding diversity in personal and local perspectives and in the context of migration history' (Hutchinson 2009: 88). She has also experimented with sound installations in conveying a dialogue in exhibitions (Hutchinson and Collins 2009). This approach personalizes dialogue through individual stories, rather than a use of oral histories as illustrative of generalized narratives presented as representative of a culture or group. The contact zone here is rooted in local place and people, rather than focusing on one journey to Australia. Another innovative 
approach suggests an exhibition does not have to 'teach' about diversity, but may seek to affect empathy and dialogue by using personal stories in a dialogical presentation, arguing for a breaking away from the use of the suitcases and national dress to pin immigrants to the past (Witcomb 2009). In contrast, recent practice at the Museum of Migration in Melbourne explores a transcultural Australian national identity through key historic artefacts in an object biography approach and reinterpretation by curators (Wehner and Sear 2010: 143). In this instance, objects in cases can be seen as the central point of contact in the contact zone.

Other exhibitions approach migration through the use of video and art installation. For example, Towards the Other (2011), in the State Museum of the History of St. Petersburg, presents videos of people talking about migration on many screens around the exhibition space. ${ }^{5}$ While Nothing is Missing, curated by Mieke Bal, invites visitors to sit in a living room and watch four TV screens with videos of mothers from diverse cultures talking to imaginary people, such as grandchildren who they never got to meet. ${ }^{6}$

There is nothing unusual, then, about exhibitions focusing on ideas and experiences of cultural diversity. However, although opening the museum to people from different cultural backgrounds may be happening, innovative ways of expressing cultural identities outside the discourses of social inclusion and a migration narrative linked to national identity are not so common. Expressions of 'new' postcolonial identities in exhibitions, it has been suggested, are outside the norm, and considered only by museums in large cities or 'avant-garde art museums' (Macdonald 2003: 6).

The key features of the examples above may be seen as the following. Typically, people from diverse cultures are considered in exhibitions predominantly within an historic context; the exhibitions also concentrate on groups. Further, many examples in the literature come from countries that have experienced mass immigration, such as Australia. In terms of the means by which cultural diversity and migration are expressed, many examples use objects in glass cases. Recent experimental approaches concern the use of the dialogic on personal, historic experiences expressed through people's own words in text and sound.

I argue for a more creative presentation: of present day rather than past cultural diversity and migration, which is not based on glass cases and themed-based text. This builds on the thrust of both the dialogic approaches and the visual art examples considered in this section. These approaches confront the assumptions that a display language and structure from traditional museum exhibitions always have to be there. It calls into question Ruth Phillips' point that a curator can act as a 'facilitator' putting across messages from the community, yet produce exhibitions that are 'always built on top of layers of information, interpretation, and museological conventions that have accumulated over time' (Phillips 2003: 164). As a curator, the most important aspects that should underpin an exhibition, where the subject is individual people, are: gathering the actual experience of cultural and personal identity by people from outside the museum, and creating a physical framework to convey this to the visitor using material and visual media as well as words.

\section{Destination Donegal - the Irish context}

In contrast to countries such as Australia, Ireland has only recently seen levels of immigration that have led to a more culturally diverse society, with asylum seekers and economic migrants from all over the world. This is a significant change to Irish society, and to Donegal, a county situated in the north west of Ireland. In Ireland, the more typical way of looking at migration in museums is through the experience of nineteenth century mass migration from Ireland. The Cobh Heritage Centre, Cork, for example, presents this story from the perspective of a major port, a narrative approach based on national political and economic history. Whereas the UlsterAmerican Folk Park in Northern Ireland is an open-air museum of reconstructed historic buildings focusing on the history of local people who migrated to America. ${ }^{7}$

The subject of contemporary cultural diversity has rarely been considered in Irish museums, despite the fact that the economic boom of the 1990s contributed to an almost tenfold increase in inward migration. ${ }^{8}$ The social inclusion debate in Donegal - a county of the Republic of Ireland bordering Northern Ireland (UK) - is dominated by an historic and deeply rooted discussion of difference between Protestant and Catholic communities, and includes 
spotlighting of the Irish Traveller community as a cultural 'Other'. Only recently has there been any consideration of new immigrants from around the world in social inclusion driven policy initiatives. There is no permanent display about contemporary cultural diversity in Ireland, though recently a small number of temporary exhibitions have taken place. For example, Postcards from Mosney, Migrations at the Belfast Exposed Gallery in 2006, enabled asylum seekers to write about hostel conditions on a postcard to the government in the context of participating in an art project (Haughey 2010). This created a dialogue between asylum seekers and the government that was communicated to visitors. In 2006, the Northern Ireland Museums Council toured, Our People, Our Times, which placed present day cultural diversity in an historical context. ${ }^{9}$ This pioneering exhibition broke new ground by identifying worldwide cultures in Northern Ireland. It presented an historic, text-based narrative with cased objects, which promoted a multicultural government message. In the Republic of Ireland, A Sikh Face in Ireland (2010), displayed photographic portraits of Sikh people in Dublin, and showed aspects of a single cultural group through thematic display boards, which included personal testimony. ${ }^{10}$ This aimed to counter racism and stereotypes, and was created by the Sikh community themselves.

Exhibitions about people, their life stories and their personal things have been done before. However, the Destination Donegalexhibition was distinctive in the following ways. It was one of the very few exhibitions about recent contemporary cultural diversity, and is of a different style and content to previous exhibitions. Further, it considered immigration in the present day, rather than emigration in the nineteenth century. In addition, immigration experiences in Donegal were considered as individual experiences, not as experiences of particular ethnic groups. Finally, the exhibition focused on a variety of people from different social backgrounds and a variety of places around the world, not just those considered socially excluded. The exhibition further contributes to our international understanding of museums and cultural diversity, because it contrasts with other examples in the museum studies literature. Ireland is a different location, compared to previous examples from countries with long histories of immigration such as Australia.

\section{Destination Donegal - The Curatorial process: approaches and methods}

From the examples presented above, there are those that illustrate a social history perspective (Hutchinson 2009), an art perspective such as Towards the Other, and a material culture studies perspective (Wehner and Sear 2010). Destination Donegal was created by blending curatorial approaches from social history, contemporary art practice and material culture studies to make an exhibition as 'contact zone'. ${ }^{11}$

Social history curatorship informed the approach by making people the subject of the show. Social history brings people into exhibitions, and foregrounds personal testimony in exhibitions (Fleming 2010). It engages with people from outside the museum walls in order to advocate, through practice, that museums are for people. This approach is in line with "new museology' (Vergo 1989), despite the contribution of social history curatorship being undervalued in previous literature concerning the new museology (O'Neill 2010: 38). Yet the social history approach is not deeply rooted in Irish museums. Destination Donegal aimed to put people at the centre of the exhibition, not as illustrative examples of particular themes, or as particular ethnic groups, or as part of an historical curatorial narrative, but as subjects in themselves. People's experiences of cultural diversity today were documented through collecting personal effects and clothes, taking portrait photographs and carrying out filmed interviews about their lives, as is used in contemporary collecting initiatives in social history. The methodology of gathering people's experiences from an informal network of family and friends, rather than looking systematically for representatives of typical groups was influenced by the study of French cooking habits by Luce Giard under the remit of Michel De Certeau's The Practice of Everyday Life: Living and Cooking (De Certeau, Giard, Mayol 1998).

Contemporary art practice inspired the curatorial approach. The exhibition location in a contemporary art gallery enabled it to be created without the physical constraints of traditional museum display, such as glass cases and historic collections. The exhibition took place in the Regional Cultural Centre in Letterkenny, County Donegal, a building opened in 2006. The 


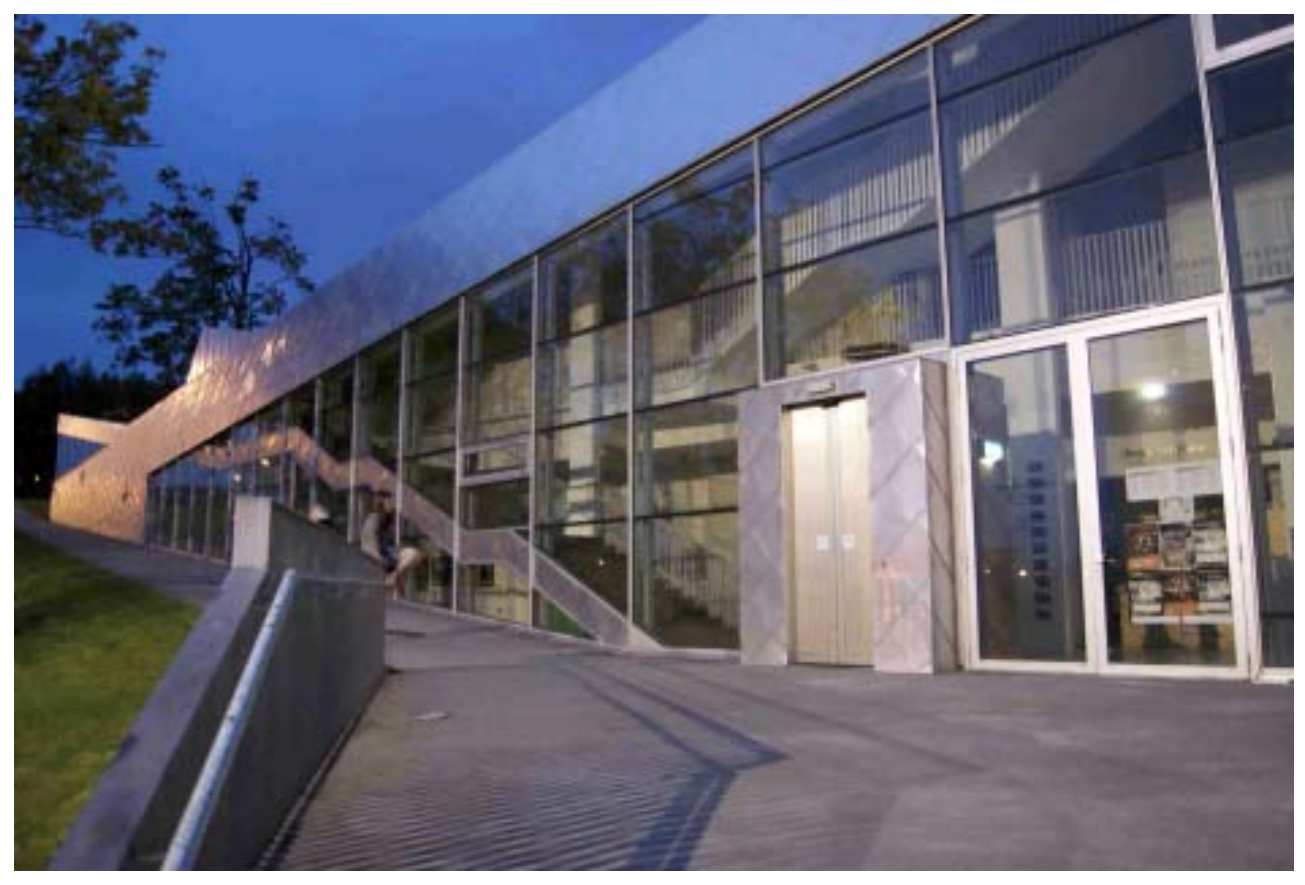

Destination Donegal Exhibition 2011: The Regional Cultural Centre where the exhibition took place, Letterkenny, County Donegal, Republic of Ireland. Photo: Harriet Purkis

physical display environment played a part, but of equal importance was the fact that the exhibition was developed within the philosophy of the Regional Centre, which has a 'socially engaged art' outlook with its core concerns 'that of addressing/responding to the specific context of Donegal and to engage, communicate, and enter into dialogue with local audiences, both residents and visitors'. ${ }^{2}$

The exhibition used photography and video, common in contemporary art installation practice, in particular ways. The focus was on the physical nature and spatial qualities of the encounter between the subjects of the show and the visitors. The contact was face-to face and eye-to-eye, and thus one based on the sense of a presence of people. The use of these media blended an art approach with a documentary approach, with form helping content to be conveyed to better effect. Portrait photographs were taken by a professional photographer as both an art portrait and as a documentary photograph. The decision to go for life-sized, headto-toe portraits was chosen in order to give the sense that the visitor was meeting people in the gallery, part of the non-verbal dialogue. In terms of film, people talked to camera about their life stories. Extracts of the filmed interviews were screened on living room style TV sets in the gallery, showing moving images of the people - a more animated interpretation of a moving video portrait such as ' 60 Minutes of Silence' by the artist Gillian Wearing. ${ }^{13}$ These were next to the portrait photographs and reinforced the still image with moving mannerisms to effect a bringing of people to life. From a distance, the people could be seen on the screens, animated, moving and talking.

A material culture studies approach also influenced the exhibition. The use of an everyday set of clothes from each person was inspired by the artist Joseph Beuys' art work 'Felt Suit' (1970). In the exhibition, the clothes acted as a self-portrait in material form. The clothes added a real, physical dimension to the communication strategy. The clothes and the images of the people interacted in the gallery space, materializing a material culture studies perspective which purports that objects and humans interact and give meaning to one another (Gell 1998, Tilley 2006, Miller 2008). 


\section{The Curatorial Process: Involvement of Participants}

The exhibition gathering process aimed to build on existing informal relationships at individual levels, to create personal and meaningful conversations based on trust. The power in the exhibition process lay with the participants who chose the content to be shown, and with the curator who determined the physical layout and design. The individuals brought with them their own reasons and motivations for becoming involved, which rendered the content of the exhibition varied.

Twenty people were approached who lived in County Donegal. The aim was to find individuals from an array of cultural backgrounds and countries around the world, a span of ages, with an equal mix of male and female. ${ }^{14}$ The intention was not to find representatives from particular communities or groups, but to seek out individuals who were willing to share their lives in public. The starting point was people who had a connection to the Regional Cultural Centre. For example, one was a volunteer at the Centre, another was a neighbour. In addition, three people who had sought asylum in Donegal were approached by the Social Inclusion Programme of Donegal County Council, of whom two agreed to become involved, a woman who had gained asylum and a man who had not. The first contact was by telephone and informal meetings, through an intermediary in the Regional Cultural Centre or Social Inclusion Programme. It was explained that an exhibition about people from different cultural backgrounds was being set up in order to show the culturally diverse

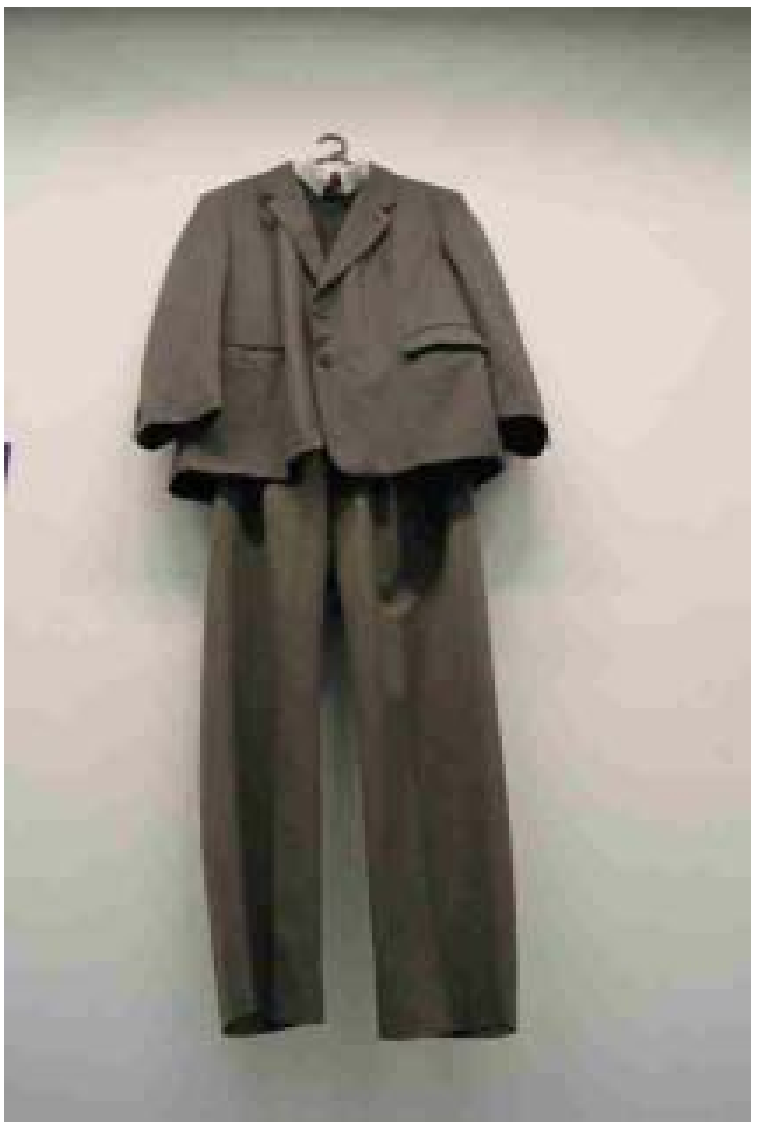

Destination Donegal Exhibition 2011: Mr R.P. Mehan's suit displayed in the style of 'Felt Suit' (1970) by Joseph Beuys. Photo: Harriet Purkis nature of local society, and that it would involve sharing their stories, personal things and photos, as well as new filmed interviews and portrait photos. The collaborative nature of the exhibition process was also explained, in terms of people being able to select for themselves which aspects of their lives to share. After this process, nine individuals and one group of three became involved.

The next stage was for the curator to meet and talk through the exhibition with each individual, and a letter of invitation was given to each person. The anticipated final layout and arrangement of material in the gallery space was discussed in personal tours of the gallery. Next, filmed interviews were set up in people's homes or at the Regional Cultural Centre, depending on the choice of the person. By engaging with, and talking to, the 12 people, personal and emotional aspects of their lives were captured on film. While the interviewer used guidance questions, these were open questions designed to encourage people to tell their own stories. The interviewer sat behind or just in front of the camera, out of view. This meant that the people were looking at and talking directly to camera. The filming involved close-up shots of people's faces. Agreement was 


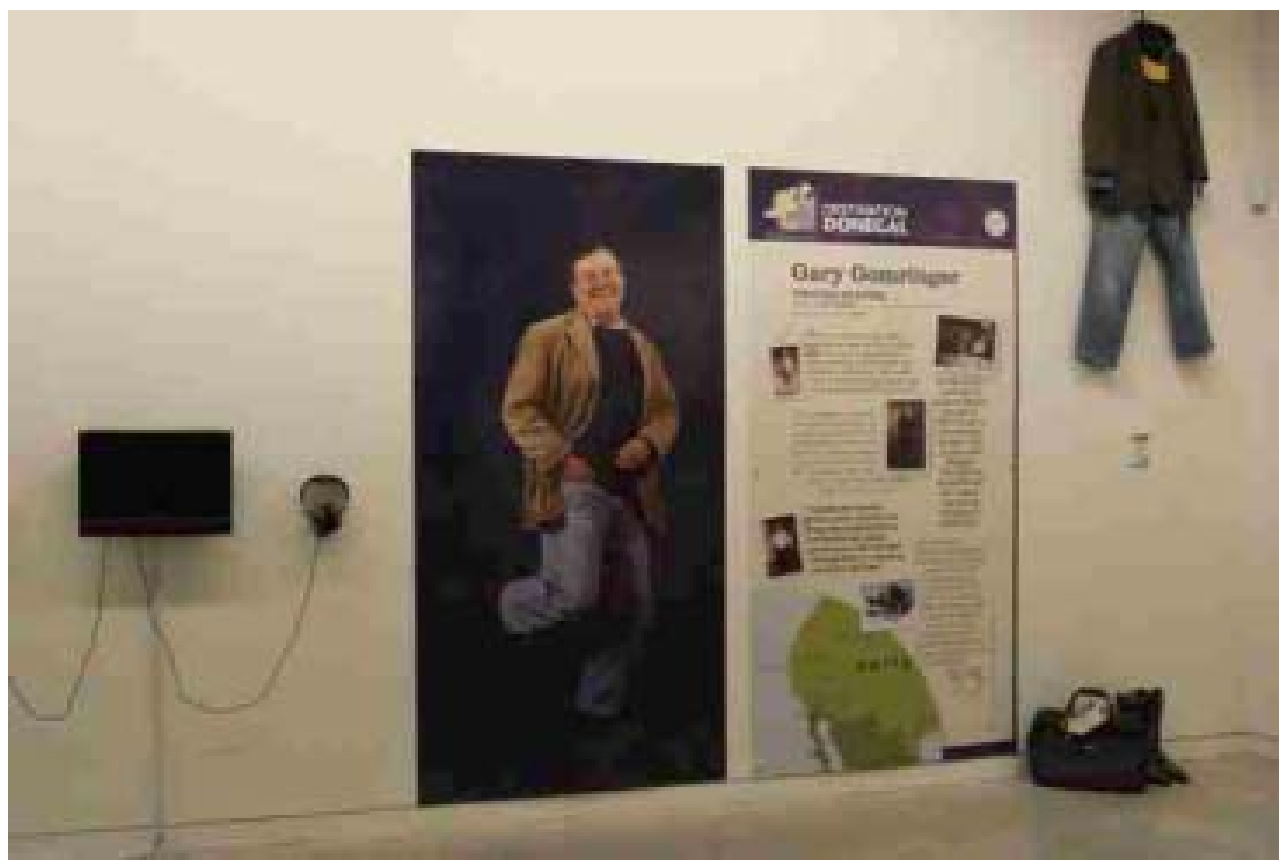

Destination Donegal Exhibition 2011: Mr Gary Gomringer presented in the exhibition featuring video interview, photographic portrait, clothes, bag, shoes and quotations and family photograph. Photo: Harriet Purkis

confirmed after filming concerning which extracts would be shown in the gallery, and which written quotations would be put on display boards. Family photos, personal objects, a set of everyday clothes and shoes and, in some cases, traditional clothing, were lent to the exhibition for display. A photo shoot was arranged for each person. After the exhibition, the curator carried out evaluation interviews. The purpose was to find out about the participants' views and feelings about both the process and the presentation of themselves in the completed exhibition. These were subjective interviews carried out by the curator rather than an outsider.

The content actually created is shown through evidence used below in the form of: details of the stories shared by the participants, comments about the exhibition process made in sound recorded summative evaluation interviews with the participants, and visitor feedback. ${ }^{15}$

The content of the exhibition consisted of personal stories of being an immigrant in Donegal. These stories included: the story of an arranged marriage; the description of Ioneliness; the boredom of life in an asylum seeker hostel; life in a newsagent shop; a doctor missing home; a jamming music session; being smuggled out of Iran; and life as a student volunteer in Letterkenny. There were references to family history, life-changing journeys, descriptions of feelings, indications of national identity and cultural differences, accounts of racist incidents, and discussions about children. The assortment of content contributed to the prominence of the individual. There were no fixed categories of themes, only individual contributions. The quotations below from the filmed interviews give a flavour. An elderly Asian man talked about local history by discussing his newsagents shop:

Barr's Newsagents was across from the post office on the Main Street. Thursday night was the best night of the whole lot. I used to get 1150 Derry People. I used to sell 600 on a Thursday night. 
A young Ukrainian woman reflected on her connections home and away:

I miss my sister so much, she is younger than me. It doesn't matter where I am, I always miss my country. But, now I feel Letterkenny like I am home. I know people here. I have a lot of friends.

A woman from Mumbai described isolation in her early days in Donegal:

I think it was very hard because I had no friends. I was lonely. His friends from work would come and ask, "Do you watch Coronation Street?"I had no idea what they were talking about.

Summative evaluation interviews with participants revealed they felt happy that they had been presented genuinely. One contributor reflected:

I thought that this thing was just representing ME. This is me, this is my real life.

The success in gathering frank and autobiographical accounts from people depended on the willingness and motivations of the participants, and on a relationship based on trust between curator, filmmaker and participants. In this way, 'mini dialogic contact zones' were created while gathering material. In some cases, being friends and neighbours with those interviewed influenced the process of contact and eased the sharing of difficult stories. For example, one woman was able to tell her story of escape from Iran for the first time because she knew the cameraman, as she tells in her evaluation interview:

Maybe because I know Jeremy (Jeremy Howard, filmmaker) and I just sat down and I was talking to him. Beforehand, maybe I was thinking, "Do I want to share it all?" And the fact Jeremy was a friend, I know him, that was easy.

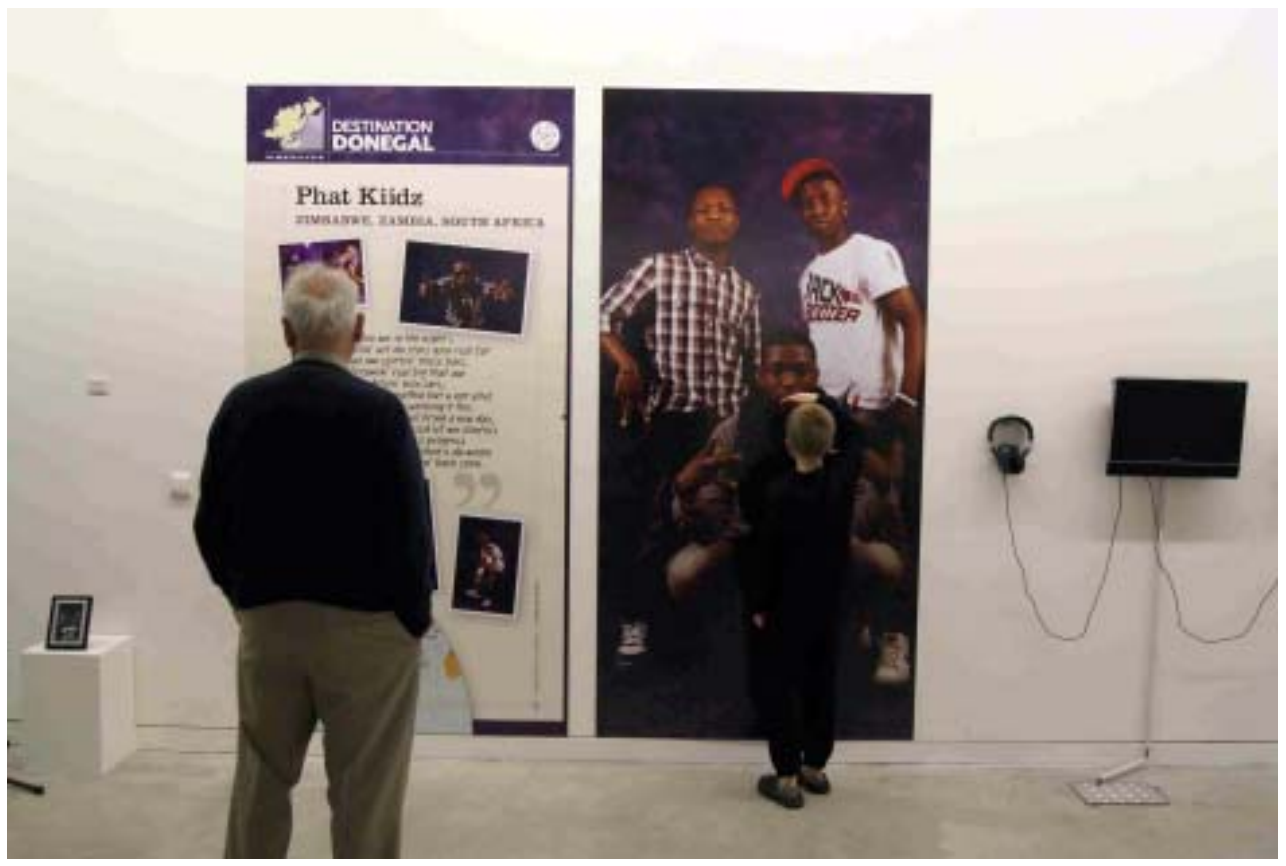

Destination Donegal Exhibition 2011: Visitors meeting the Phat Kiidz, showing the lifesize photograph. Photo: Harriet Purkis 
People had different motivations for becoming involved that led to particular content choices by the participants themselves. For example, the teenage members of the band the 'Phatt Kiidz' saw the exhibition as a chance to promote the band. Their video interview included them singing informally, with a posed portrait photo:

It was a good chance for us to get our music out as well, so we kinda used that opportunity. The photo shoot as Phatt Kiidz, it's the first we have done, and we were really excited for weeks before that, we felt like celebrities if you want to put it that way, going to our first photo shoot.

The everyday personal clothing that was borrowed gave a sense of the individual, through material and physical means. As one participant from America said, it did show what he wore most of the time:

Then the clothing, that's pretty much what I wear, I don't really care much any more about, I like my cowboy boots, I feel comfortable in them, I always wear them, and otherwise I keep telling people I'm a blue jean kinda guy.

Two reflections from the evaluation interviews with participants about the clothing reveal it holds meaning about their own personal sense of national and cultural identity as well. A South African lady said:

And at least with the green jacket (Springboks rugby jacket) that represents my country you know.

And one of the Phatt Kiidz music group said:

The hats symbolize us as a group, us as a person. It's nothing to do with, 'Rappers wear hats', it's just who we are.

Analysing design and communication in the final installation

The design and communication strategy of the final installation facilitated the impression of visitors 'meeting' the individuals. It set up a structure or physical form where participants were communicating directly to visitors. This visitor experience was shaped by the form and design of the exhibition space. The form of the contact within the exhibition as zone or space was created through a particular language of display, based on the use of the visual and material rather than principally words. On a structural level, this was an installation that aimed to be an empathetic interface between visitors and subjects. This was achieved by accentuating the human face and body through photographs, film, and clothes. Of course, the content of the peoples' stories was fundamental; the use of visual and material media enhanced the visitor interest in these.

The design of the exhibition was key to the way in which the contact zone was produced. Social history exhibitions commonly use first person quotations and objects, and the importance of presenting personal stories in exhibitions wishing to create empathy and understanding has been stressed as well. Sandell (2007: 114) underlines the power of personal stories portrayed in exhibitions for giving 'humanistic connections', and 'identification with the subjects on display' between visitors from different cultural backgrounds to the subjects. For Shultz too, spotlighting people in exhibitions are important, 'The presence of people in an exhibit has a powerful impact on learning, as it helps visitors make a personal and emotional connection to what they are seeing' (Schultz 2011: 7). However, allusion to how this is achieved through design methods is limited. Sandell (2007: 114) maintains that visitors connect to their own biographies more easily through media used in museum exhibitions that are also used in everyday communication such as TV and film. Further, Kratz (2002: 91) describes large-scale photographs and closeup faces as important vehicles in mediating 'between those who create exhibitions and exhibition visitors'. Within literature about photography and images more generally, the importance of the face is considered vital when communicating emotion (Sontag 2003).

The elements of the exhibition that achieved non-verbal identification by visitors with the subjects on display are discussed below. Each element described belonged to a larger unit, with 
clothes, a filmed interview on a TV, and a board of quotations extracted from the filmed interviews with family photographs. All elements worked together to produce the effect in the final installation. Words and text were used in the exhibition in the form of written quotations from participants on display boards, sound tracks from filmed interviews and an introduction panel by the curator. This panel added a curatorial voice and clarified that all the content was from the people featured, and that the curator had designed the space for visitors to 'meet 12 individuals who are all immigrants to Donegal' ${ }^{16}$ Life-size photographic portraits

The visitor experience of 'meeting' the people on show was embodied in the visitors' negotiation of the exhibition space. For example, they met eye-to-eye with the participants in ten life-size photographic portraits. The visitors' eyes, as well as their whole bodies were at the same level as the portrait. The design features that enhanced the visitor experience were the large size and unframed nature of the images. Furthermore, the person in the photograph was looking directly into the camera and therefore directly out of the picture into the gallery. The hanging of the photograph at ground level meant the feet in the image touched the ground, matching the visitors' body, and suggesting a meeting as in a virtual shaking of hands. The portraits were used to enrich the visitors' experience of the first person stories they read and heard.

\section{Faces on film}

Filmed interviews appeared on a TV like a domestic television set beside the portraits. The design concept, which heightened the way the visitor became familiar with the participant, was through seeing moving faces in conversation on screens. The voices were silent as visitors approached, because the sound was delivered through headphones. The moving images of faces were sometimes looking directly at the camera, sometimes away as in a conversation, as the interviewer had sat behind the camera during the interview. Many were shown in their own living room chairs, while others were filmed in the gallery itself, providing a domestic or gallery background, rather than a studio or a less familiar backdrop which may have made the people appear less ordinary. When the headphones were lifted and the conversation shared, an effect of intimacy between the visitor and the person on show was created. On one wall in the gallery a projected film of all the films together was playing with the sound turned up. This provided an overspill of voices into the gallery, of talking, laughter and songs. In this way, audio was used to create a sense of living people being in the gallery, adding to the impression of a gathering space.

\section{Everyday Clothes}

Each person's set of everyday clothes hung beside the portrait. The aim of the design here was to produce a human connection between participants and visitors. For instance, rather than putting clothes on mannequins, they were hung from a hook on the wall by ordinary hangers, creating a feeling that they came from a wardrobe. The un-ironed and worn nature of the clothes added to this impression. A pair of shoes was put on the floor under the clothes as in a bedroom or hallway at home. Personal clothing was displayed in order to affect an emotional and personal response from the visitor, through the use of physical objects (Dudley 2010). The clothes had an agency as material culture, communicating both the physical body or presence of the person together with signifying their personal identity -through their smell, wear and general sagging as well as personal style (Schneider 2006). In addition, personal clothing and personal objects were contact points in the zone, acting as 'social objects', as 'engines' for conversation and dialogue (Simon 2010). Observations of visitor behaviour supported this. For example, a family group discussed the smell and sagging of a man's suit on display, and looked at his shoes. One of them knew the man in question and said, 'That's definitely R.P.'

Interactivity

A hands-on area for visitors invited contributions through interactivity. Activities included making a simple artwork from Lego bricks based on colours and shapes in national flags. There 


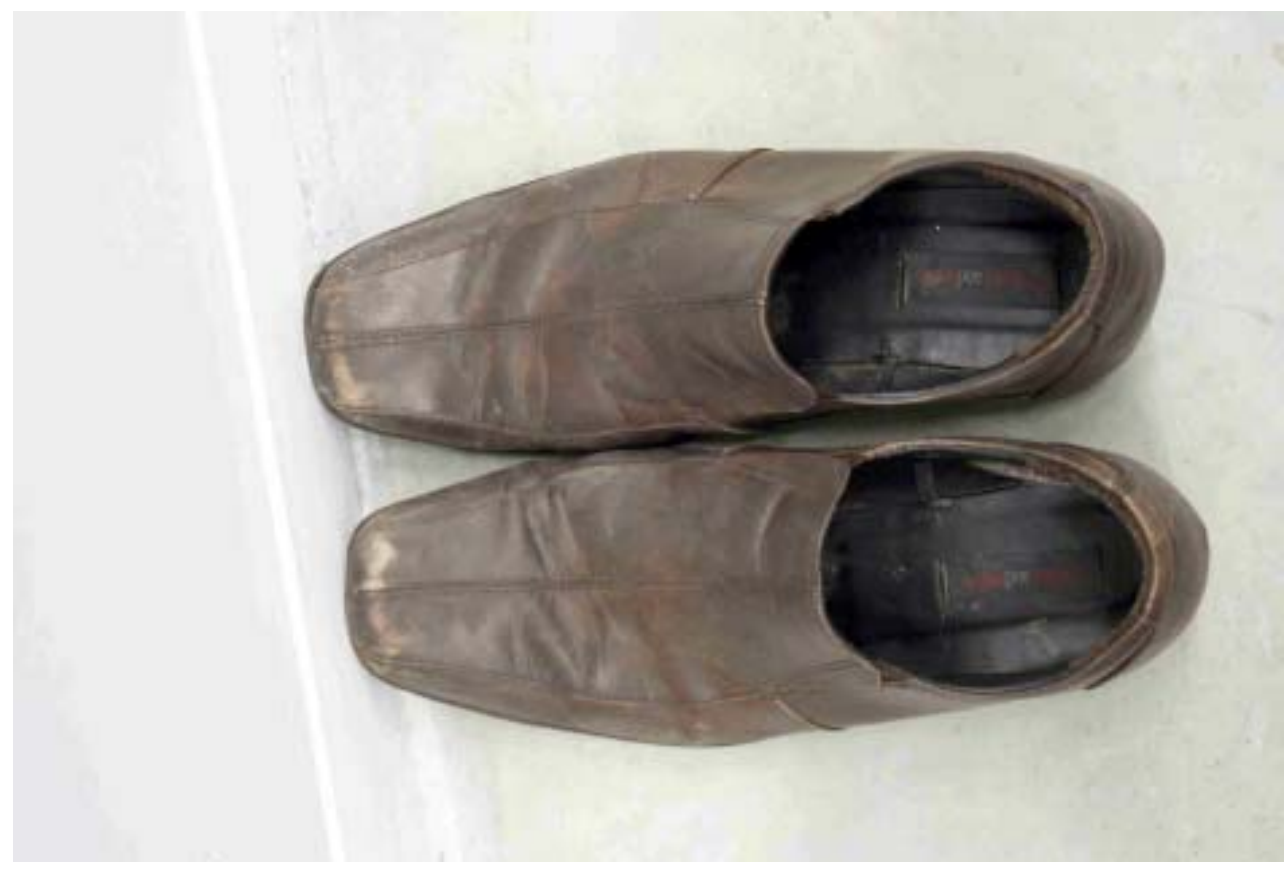

Destination Donegal Exhibition 2011:MrR.P. Mehan's shoes displayed on floor underneath a head-to-toe life-size photographic portrait. Photo: Harriet Purkis

was also an opportunity for visitors to record their own story about migration on camera in a video booth, which then became part of the exhibition for future visitors to see. Yellow post-it-notes were available to write on, about either feedback on the exhibition or for visitors to write about an object they would take with them if they emigrated. These features allowed for visitor input and engagement through writing, talking and making.

\section{Visitor and participant responses}

The aim of the exhibition - to create emotional and personal contact between participants and visitors - can be seen to have been achieved through the evidence of responses through a visitors' book and yellow post-it notes. Visitor remarks made during the show to staff were also noted down. However, no formal visitor surveys were made. The exhibition was well attended with over 4,000 visitors. Staff reported that a typical visitor would take about an hour to go around the exhibition, spending about six minutes at each section. Written visitor responses included:

I felt as if I was having a personal connection with each person.

And:

Fascinating insights presented in a warm and accessible way.

And:

The clothes were a great way of feeling the person was here in the room.

In addition, evidence from participant summative evaluation interviews reveals that the form of the exhibition had limitations, yet succeeded in its aim of presenting individuals effectively:

It was definitely me yeah; it wasn't the whole of me, but a big part of me. But you've got to edit an hour's worth of information into 15 minutes; something's got to give.

So I felt comfortable with it yeah. 


\section{Concluding Thoughts}

The exhibition Destination Donegal has been used as an example to argue that curatorial production focused on people can achieve a contact zone. It has considered the political, social and museum context in which a cultural diversity exhibition is made as important, but has also shown in practice how the nature and form of contact in such an exhibition can be influenced by participants and by the curatorial and production process. The paper aims to contribute to the theoretical discussion around the dialogic contact zone idea, by presenting personal and present day portraits of culturally diverse individuals in practice. It demonstrates that there is considerable value in non-verbal aspects of the exhibition form, which use visual and material sources to represent individuals, within a language of art installation.

This paper has argued that making an exhibition as a contact zone in practice can help reframe the contact zone concept in theory. The contact zone concept is commonly used in museum studies when discussing cultural diversity, to epitomize a contact or collaboration with culturally diverse groups to offer a reinterpretation of historical colonial collections or power relationships. In contrast, the contact zone concept has been used here in an exhibition about present day and individual experiences of immigration and cultural diversity. Destination Donegal set out to be a visible and tangible 'contact zone' in order to contribute a unique realization of the contact zone in the following ways. First, it focused on contact between individual people in present day society, rather than applying the contact zone to historic museum collections or colonial history. Second, it created a physical installation that acted as a zone or place of meeting and engagement. Thirdly, the nature of the content in the exhibition zone was personal and emotional, coming from individuals' stories as they wanted to tell them in public. The content and nature of the contact in the zone was influenced, in most cases, by existing positive relationships between project members and the participants, which aided the gathering of honest and personal accounts. Fourthly, it used visual images and material things to enhance visitors' contact with, and empathetic understanding of, people, as opposed to foregrounding dialogue through words and text. Finally, interactive elements in the display, and also the collaborative approach to inviting content from participants, can be seen as the making of a dialogic type of contact zone, because of the way these involved a two-way communication. This paper may also contribute to a more general discussion about design strategies using nonverbal communication in exhibitions that display people and their personal identity, not directly related to cultural diversity.

Received: 8 August 2012

Finally Accepted: 18 October 2012

\section{Notes}

1 Destination Donegal, an exhibition curated by the author at the Regional Cultural Centre, Letterkenny, Co. Donegal, Ireland from 25 March -7 May 2011. The exhibition was conceived as part of a social inclusion initiative of Donegal County Council called, 'One Donegal', which aims are to embrace and celebrate cultural diversity, and challenge racism through a range of public events. It is funded by Peace and Reconciliation funding through the Peace III programme, a programme promoting peace-building work in the border regions of Ireland and Northern Ireland following the period of sectarian conflict referred to as 'The Troubles'. For further details see the 'One Donegal' booklet produced by Donegal County Council http://www.donegalcoco.ie/NR/rdonlyres/98ACD7E5-E9E5-4CCF-881FF63FC7CFCOD3/0/culdiv2010.pdf

2 An art installation uses a variety of media including video, objects, and sound to make a three-dimensional work in a gallery space. It is defined by the Cambridge Advanced Learner's Dictionary and Thesaurus as, 'a form of modern sculpture where the artist uses sound, movement or space as well as objects in order to make an often temporary work'. http://dictionary.cambridge.org/dictionary/british/installation_4

3 A conference about museums and the contact zone was held in 2011. 'Re-visiting the Contact Zone: Museum, Theory and Practice', 17-21 July, Linkoping, Sweden. 
4 See for example the projects and publications on line at the Research Centre for Museums and Galleries based at the School of Museum Studies, Leicester University http:// www2.le.ac.uk/departments/museumstudies/rcmg/themes

5 Curated by Maria Veits and Ana Bitkina of TOK(Produced and co-curated by Eva Koppen of the Netherlands Institute Saint Petersburg. See http://www.miekebal.org/artworks/ exhibitions/towards-the-other

6 http://www.miekebal.org/artworks/installations/nothing-is-missing/2006-2010

7 The Ulster American Folk Park, Omagh, Co Tyrone, N. Ireland and the Queenstown Story, Cobh Heritage Centre, Cobh, Co. Cork, Ireland.

8 The total number of immigrants in the total Irish population in 1987 was 17,200; in 2007 there were 109,500. Source: Central Statistics Office, Ireland Report, September 2011.

9 See www.learningmigration.com for 'Our People Our Times' document for the Northern Ireland Museums Council, 2006.

10 A Sikh Face in Ireland was first shown at the Chester Beatty Library in Dublin in 2010 and then toured to venues in Ireland. It was produced with the Forum on Migration and Communications and the Irish Sikh Council, as a project that would contribute to anti-racist education and transcultural understanding. See http://www.cbl.ie/Exhibitions/PastExhibitions/A-Sikh-Face-in-Ireland.aspx

11 The exhibition had a research context, a practical element of $\mathrm{PhD}$ research at the University of Ulster, Northern Ireland.

12 Shaun Hannigan - Director of the Regional Cultural Centre, Co. Donegal Ireland on page 4 of 'Time' exhibition catalogue, Regional Cultural Centre, Letterkenny 2005, 3-6

13 '60 Minutes of Silence' 1997, by the Turner Prize winning British artist Gillian Wearing, was a video of 26 police officers sitting for a photograph. At first it looks like a still image, but small movements reveal it to be a moving portrait. See http://news.bbc.co.uk/1/hi/special_report/ 1997/turner_prize/36273.stm

14 The participants included a male doctor from the Sudan; a male asylum seeker living in a hostel from Iraq; a female Ukrainian student volunteer for a youth information service; a mother from South Africa who had gained asylum; three 18 year old boys in a music group from Zambia, Zimbabwe and South Africa; an elderly American man who volunteered at the Regional Cultural Centre; a female German Council worker and horse rider; an elderly male newsagent from Pakistan; a female shop owner from Iran; a mother from India.

15 These quotations are extracts from filmed interviews of the participants used in the exhibition, and extracts from sound recorded evaluation interviews of the participants. A total of 20 semi-structured interviews of 13 participants were conducted. Twelve interviews about people's life stories and key events were filmed for exhibition use, and eight summative evaluation interviews were sound recorded and transcribed. All were carried out between January and May 2011. The quotations from visitors come from the Destination Donegal visitor comments book, yellow post-it notes used for visitor responses and staff notes of what visitors had said while visiting. Sontag, S. (2003) Regarding the Pain of Others, New York; Farrar, Straus and Giroux Tilley, C. (2006), 'Theoretical perspectives: introduction', in Chris Tilley, Webb Keane, Susanne Kuchler, Michael Rowlands and Patricia Spyer (eds), Handbook of Material Culture, 7-12, London: Sage; Vergo, P. (ed) (1989) The New Museology, London: Reaktion Books; Wehner K. and Sear M. (2010) 'Engaging the Material World: Object knowledge and Australian Journeys', in Sandra Dudley (ed) Museum Materialities: Objects, Engagements, Interpretations, 143-161, London and New 
York: Routledge; Witcomb, A. (2003) Re-Imagining the Museum: Beyond the Mausoleum, London: Routledge; Witcomb, A. (2009) 'Migration, social cohesion and cultural diversity:

Can museums move beyond pluralism?', Humanities Research 15 (2) 49-66

16 Harriet Purkis, Curator's Introduction text panel, Destination Donegal Exhibition 2011.

\section{References}

Alberti, S. and Lynch B. (2010) 'Legacies of prejudice: racism, co-production and radical trust in the museum', Museum Management and Curatorship, 25 (1) 13-35

Askins, K. and Pain R. (2011) 'Contact zones: participation, materiality and the messiness of interaction', Environment and Planning D: Society and Space, 29 (5) 803-821

Bennett, T. (2006) 'Exhibition, Difference and the Logic of Culture', in Ivan Karp, Corinne A. Kratz, Lynn Szwaja and Tomas Ybarra-Frausto (eds) Museum Frictions: Public Cultures/Global Transformations, 46-69, Durham and London: Duke University Press

Boast, R. (2011) 'Neocolonial collaboration: Museum as Contact Zone Revisited', Museum Anthropology, 34 (1) 56-70

Bonnell, J. and Simon, R. (2007) 'Difficult' exhibitions and intimate encounters', Museum and Society, 5 (2) 65-85

Cameron, F. and Kelly L. (eds) (2010) Hot Topics, Public Culture and Museums, Newcastle: Cambridge Scholars

Clifford, J. (1997) 'Museums as Contact Zones', in Clifford, J. Routes: Travel and Translation in the Late Twentieth Century, 188-219, Cambridge, Massachusetts and London: Harvard University Press

Crooke E.M. (2007) Museums and Communities, Oxon: Routledge

De Certeau, M., Giard, L., Mayol, P. (1998) The Practice of Everyday Life Volume 2: Living and Cooking, Translated by Timothy J. Tomasik, Minneapolis: University of Minnesota Press

Doering Z. and Lakshmi R. (2012) 'Introduction to the Special Issue' Curator 55 (1) 1-2

Dudley, S. (2010) Museum Materialities: Objects, Engagements, Interpretations, London: Routledge

Fleming, D. (2010) 'Social history in museums: 35 years of progress?' Journal of the Social History Curators Group, 34, 39-45

Gell, A. (1998) Art and Agency: An Anthropological Theory, Oxford: Clarendon

Golding, V. (2009) Learning at the Museum Frontiers: Identity, Race and Power, Farnham: Ashgate Publishing

Haughey, A. (2010) 'Dislocations: Participatory Media with Refugees in Malta and Ireland', in H.-L. Skartveit and K. Goodnow (eds) Changes in Museum Practice: New Media, Refugees and Participation, 1-16, Oxford: UNESCO Museum of London and Berghahn Books

Hutchison, M. (2009) 'Dimensions for a Folding Exhibition: Exhibiting Diversity in Theory 
and Practice in the Migration Memories Exhibitions', Humanities Research, 15 (3) $67-92$

Hutchison, M. and Collins L. (2009) 'Translations: experiments in dialogic representation of cultural diversity in three museum sound installations', Museum and Society, 7 (2) 92-109

Isar, Y. and Anheier, H. (2011) Cultures and Globalization: Heritage, Memory and Identity, London: Sage

Kratz, C. (2002) The Ones That are Wanted: Communication and the Politics of Representation, California: University of California Press

Long, J. J. (2011) 'In the contact zone: W. G. Sebald and the ethnographic imagination'(Journal of European Studies 41 (3-4) 413-430

MacDonald, S. (2003) 'Museums, National, Postnational and Transcultural Identities', Museum and Society, 1 (1) 1-16

Mason, R. (2010) 'Cultural Theory and Museum Studies', in Sharon MacDonald (ed) $A$ Companion to Museum Studies, 17-32, Maiden, MA: Blackwell

Message, K. (2009) 'Review Article(Museum Studies: borderwork, genealogy, revolution', Museum and Society, 7 (2) 125-132

McLean, F. (2008) 'Museums and the Representation of Identity' in Brian J. Graham and Peter Howard (eds) The Ashgate Research Companion to Heritage and Identity, 283-296, Aldershot: Ashgate publishing

Miller, D. (2008) The Comfort of Things, London: Polity

Nederveen Pieterse, J. (1997) Multiculturalism and museums: Discourse about others in the age of globalization, Theory, Culture and Society 14 (4) 123-46

O'Neill, M. (2010) 'SHCG: A community of practice based on empathy and rigour', Journal of the Social History Curators Group, 34, 35-38

Pahl, K. and Pollard, A. (2010) 'The Case of the disappearing object: narratives and artefacts in homes and a museum exhibition from Pakistani heritage families in South Yorkshire', Museum and Society, 8 (1) 1-17

Phillips, R. B. (2003) 'Community Collaboration in Exhibitions: Introduction', in Laura Peers and Alison K. Brown (eds), Museums and Source Communities, 157-70, New York: Routledge

Pratt, M. L. (1991) 'Teaching and classrooms', Profession 91, 33-40, New York: MLA

Sandell, R. (2003) 'Social inclusion, the museum and the dynamics of sectoral change', Museum and Society, 1 (1) 45-62

Sandell, R. (2007) Museums, Prejudice and the Reframing of Difference, Oxon: Routledge

Schneider, J. (2006) 'Cloth and Clothing', in Chris Tilley et al (eds) Handbook of Material Culture, 203-220, London: Sage

Schultz, L. (2011) 'Collaborative museology and the visitor', Museum Anthropology, 34 (1), $1-12$ 
Shatanawi, M. (2012) 'Engaging Islam: Working with Muslim Communities in a Multicultural Society', Curator, 55 (1) 65-79

Simon, N. (2010) The Participatory Museum, California: Museum 2.0

Skartveit H.-L. and Goodnow K. (eds) (2010) Changes in Museum Practice: New Media, Refugee and Participation, Oxford: UNESCO Museum of London and Berghahn Books

Sontag, S. (2003) Regarding the Pain of Others, New York: Farrar, Straus and Giroux

Tilley, C. (2006), 'Theoretical perspectives: introduction', in Chris Tilley, Webb Keane, Susanne Kuchler, Michael Rowlands and Patricia Spyer (eds), Handbook of Material Culture, 7-12, London: Sage

Vergo, P. (ed) (1989) The New Museology, London: Reaktion Books

Wehner K. and Sear M. (2010) 'Engaging the Material World: Object knowledge and Australian Journeys', in Sandra Dudley (ed) Museum Materialities: Objects, Engagements, Interpretations, 143-161, London and New York: Routledge

Witcomb, A. (2003) Re-Imagining the Museum: Beyond the Mausoleum, London: Routledge

Witcomb, A. (2009) 'Migration, social cohesion and cultural diversity: Can museums move beyond pluralism?', Humanities Research 15 (2) 49-66

${ }^{*}$ Harriet Purkis is a graduate of the University of Leicester (B.A. Economics and Economic History, M.A. in Museum Studies), and the University of Ulster (M.A. in Tourism Management). She is an Associate of the Museums Association. Currently studying for a PhD at the University of Ulster, with a Vice Chancellor's Research Scholarship, her subject is the value and meanings of contemporary, mass produced objects. She is a former Chair of the Social History Curators Group. She has worked as a practical curator recording interviews, collecting objects and making photographic and film records of people's everyday lives in exhibitions including 'Fibres, Fabrics and Fashion' at the Museum of Science and Industry in Manchester.

Contact Details:

Redbrae,

Rathmullan,

Co. Donegal,

Ireland

Purkis-h@email.ulster.ac.uk

Harriet.purkis@gmail.com

00353863603218

00447519803913 